\title{
Prostate cancer with perineural spread and dural extension causing bilateral lumbosacral plexopathy: case report
}

\author{
Stepan Capek, MD, ${ }^{1,2}$ Benjamin M. Howe, MD, ${ }^{3}$ Jennifer A. Tracy, MD, ${ }^{4}$ Joaquín J. García, MD, ${ }^{5}$ \\ Kimberly K. Amrami, MD, ${ }^{3}$ and Robert J. Spinner, MD ${ }^{1}$ \\ ${ }^{1}$ Departments of ${ }^{1}$ Neurosurgery, ${ }^{3}$ Radiology, ${ }^{4}$ Neurology, and ${ }^{5}$ Anatomic Pathology, Mayo Clinic, Rochester, Minnesota; and
2International Clinical Research Center, St. Anne's University Hospital Brno, Brno, Czech Republic
}

Perineural tumor spread in prostate cancer is emerging as a mechanism to explain select cases of neurological dysfunction and as a cause of morbidity and tumor recurrence. Perineural spread has been shown to extend from the prostate bed to the lumbosacral plexus and then distally to the sciatic nerve or proximally to the sacral and lumbar nerves and even intradurally. The authors present a case of a bilateral neoplastic lumbosacral plexopathy that can be explained anatomically as an extension of the same process: from one lumbosacral plexus to the contralateral one utilizing the dural sac as a bridge between the opposite sacral nerve roots. Their theory is supported by sequential progression of symptoms and findings on clinical examinations as well as high-resolution imaging (MRI and PET/CT scans). The neoplastic nature of the process was confirmed by a sciatic nerve fascicular biopsy. The authors believe that transmedian dural spread allows continuity of a neoplastic process from one side of the body to the other.

http://thejns.org/doi/abs/10.3171/2014.12.JNS141339

KEY WORDS perineural spread; prostate cancer; plexopathy; lumbosacral plexopathy; bilateral; oncology

$\mathrm{P}$ ROSTATE cancer is the most common cancer in men, accounting for 233,000 new cases and 30,000 deaths in the US yearly. The 5-year survival rate for patients with localized or regional disease is virtually $100 \%$, but for patients with distant lesions it drops to $28 \% .22$

The association of neurological involvement with prostate cancer as well as other pelvic cancers has been poorly understood. Recently, perineural spread along the lumbosacral plexus has emerged as a logical, anatomical etiology for select cases. The cancer cells invade the inferior hypogastric plexuses around the prostate and spread to the lumbosacral plexus using the pelvic and sacral splanchnic nerves as conduits. Once the tumor cells reach the lumbosacral plexus, perineural spread of tumor can continue distally to the arborizing nerves or proximally to the spinal nerves or even intradurally. Such cases have been described in prostate cancer $^{3,12,17}$ or cervical cancer. ${ }^{14,23} \mathrm{We}$ present a patient with prostate cancer who developed bilateral lumbosacral plexopathy that can be explained anatomically as an extension of the same process: perineural spread from one side extended to the contralateral side utilizing the dural sac as a bridge.

\section{Case Report}

History

This 64-year-old man with a history of prostate cancer diagnosed in 2008 presented to our institution in April 2014 for a second opinion for his deteriorating bilateral lumbosacral plexopathy and urinary and fecal incontinence.

In early 2008 , he had stopped taking tamsolosin, which he had previously been taking for benign prostate hyperplasia. In May 2008, he was found to have an elevated

ABBREVIATIONS CSF = cerebrospinal fluid; EMG = electromyography; FDG = fluorodeoxyglucose; $\mathrm{PET} / \mathrm{CT}$ = positron-emission tomography/computed tomography; $\mathrm{PNI}=$ perineural invasion; PSA = prostate-specific antigen.

SUBMITTED June 15, 2014. ACCEPTED December 9, 2014.

INCLUDE WHEN CITING Published online February 6, 2015; DOI: 10.3171/2014.12.JNS141339.

DISCLOSURE Dr. Capek is supported by European Regional Development Fund Project FNUSA-ICRC (No. CZ.1.05/1.1.00/02.0123). 
prostate-specific antigen (PSA) level $(6.4 \mathrm{ng} / \mathrm{ml})$ on routine screening and underwent a transrectal prostate ultrasound and biopsy. The biopsy was positive for prostate adenocarcinoma; the highest Gleason score was $4+5$. A whole-body CT scan revealed no evidence of metastatic disease. A bone scan showed increased uptake in the left sacroiliac joint, which was reported as negative for cancer on bone biopsy. Neoadjuvant hormonal therapy (with leuprolide and bicalutamide) was initiated in June 2008. Around this time the patient developed erectile dysfunction. He subsequently underwent radical non-nervesparing prostatectomy and lymph node dissection in $\mathrm{Au}-$ gust 2008. Microscopic examination was remarkable for prostatic adenocarcinoma with extraprostatic extension, positive margins, and bilateral perineural invasion (Fig. 1). The disease was staged as pT3aNOM0. Adjuvant hormonal therapy and intensity-modulated radiotherapy were administered and completed in August 2009. The patient's serum PSA subsequently became undetectable.

The patient was then asymptomatic until summer 2011, when he developed weakness and sensory loss of his left distal lower extremity. This was followed by the development of urinary incontinence and fecal incontinence, constipation, and tenesmus several months later. The patient's PSA level was $0.54 \mathrm{ng} / \mathrm{ml}$ by the end of 2011 . His weakness and numbness continued to progress, and he developed perineal and perianal numbness in 2012. The same year he received 30 sessions of hyperbaric oxygen treatment and started treatment with vitamin $\mathrm{E}$ and pentoxifylline for what was thought to be a radiation-induced neuropathy of the left L5-S1 nerve roots or the sciatic nerve without any success. The patient underwent electromyography (EMG) in October 2012. Myokymia was not reported (or noted). Nerve conduction studies were performed, and left tibial compound muscle action potentials (CMAPs) as well as left sural nerve action potentials (SNAPs) were unobtainable. The results of electrophysiological testing were considered to be consistent with a radiation-induced injury to the left S-1 nerve root or the sciatic nerve. Magnetic

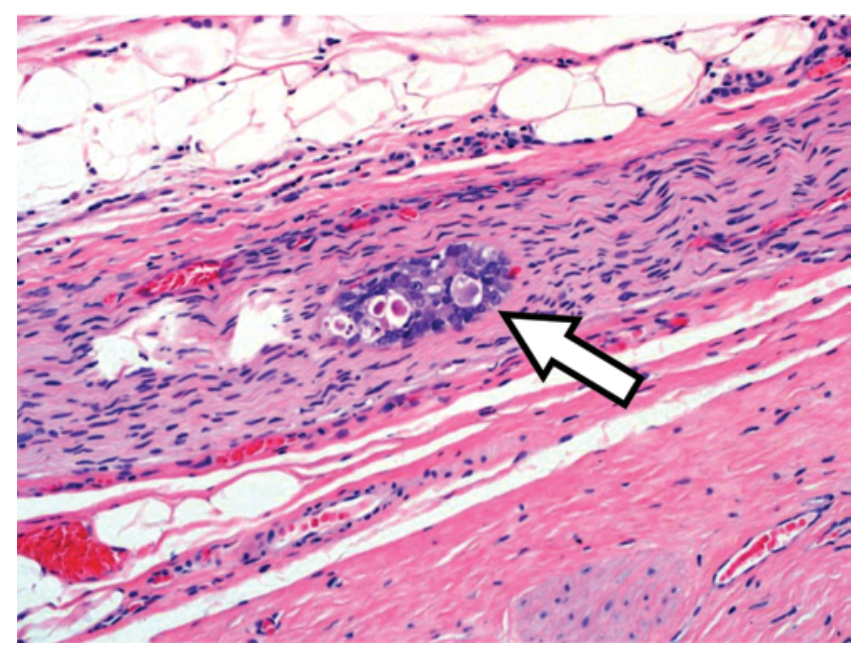

FIG. 1. Photomicrograph showing the histomorphological features of a radical prostatectomy specimen from 2008 . The arrow indicates intraneural invasion of a periprostatic segmental nerve. $H$ \& E, original magnification $\times 200$. resonance imaging in March and October 2012 showed denervation changes of the left obturator internus muscle and muscles supplied by the left sciatic nerve (Fig. 2A and B). The left sciatic nerve and left S-1 and S-2 nerves were enlarged and enhancing. The dural sac demonstrated rim-like enhancement at the S-1 level without any obvious sacral canal mass (Fig. 3A). This was presumed to represent radiation change. The patient received 60 more sessions of hyperbaric oxygen treatment, again with no response. His PSA level continued to increase and was 1.2 $\mathrm{ng} / \mathrm{ml}$ by the end of 2012 .

The patient's neurological status steadily continued to worsen in 2013, and this worsening correlated with a further increase in his PSA level $(2.04 \mathrm{ng} / \mathrm{ml})$ in May 2013. He underwent another round of hormonal therapy, which resulted in a decrease in the PSA level to $0.5 \mathrm{ng} / \mathrm{ml}$ in July 2013. By this time he needed a left ankle-foot orthosis and a stick in order to walk. In the summer of 2013 he underwent additional imaging. A bone scan performed in June 2013 was read as negative. Whole-body CT demonstrated subtle sclerosis of the right ischial tuberosity and the left inferior pubic ramus. An MRI study done in August 2013 demonstrated an enlarged left lumbosacral trunk, enlarged and avidly enhancing left S-1 and S-2 nerves, and an enlarged left sciatic nerve, with this pattern extending several centimeters distal to the pelvis. It further showed the sacral canal filled with circumferential heterogeneously enhancing lesion at the S1-2 level (Fig. 3B) continuous with the left S-1 and S-2 nerve roots. The sacral canal at this level was dilated, and multiple muscles were found to show denervation changes, all on the left side (including the glutei, obturator internus, and the piriformis muscles). The imaging was still interpreted as representing radiation change with fibrosis. At the same time the patient was fitted with a penile clamp for incontinence. Around this time he noticed weakness in his right foot, and in November 2013 he developed a burning sensation and numbness along the right lateral foot as well as circumferential perianal and penile numbness. His PSA level increased to $2.8 \mathrm{ng} / \mathrm{ml}$ in February 2014.

\section{Examination}

The patient presented to our institution in April 2014 for further evaluation. He had an extensive work up by a neurologist, a neurosurgeon, a medical oncologist, and a urologist. On presentation, he was found to have no strength in his distal left lower extremity (0/5), left hamstring strength of 2/5, and left quadriceps and iliopsoas strength of 4/5. His right foot dorsiflexion was $4 / 5$ and his right plantar flexion and knee flexion were $3 / 5$. The remainder of the right lower extremity showed normal strength. There was decreased sensation in the left L-5 and S-1 distribution and the right S-1 distribution. Ankle jerks were absent bilaterally, but other reflexes were normal. EMG confirmed bilateral lumbosacral plexopathy, more prominent on the left, without myokymia. The PSA level was $5 \mathrm{ng} / \mathrm{ml}$.

\section{Imaging}

Imaging studies included multiparametric MRI of the head, lumbar spine, and pelvis including MR neurography and pharmacokinetic perfusion analysis and ${ }^{11} \mathrm{C}$-choline 

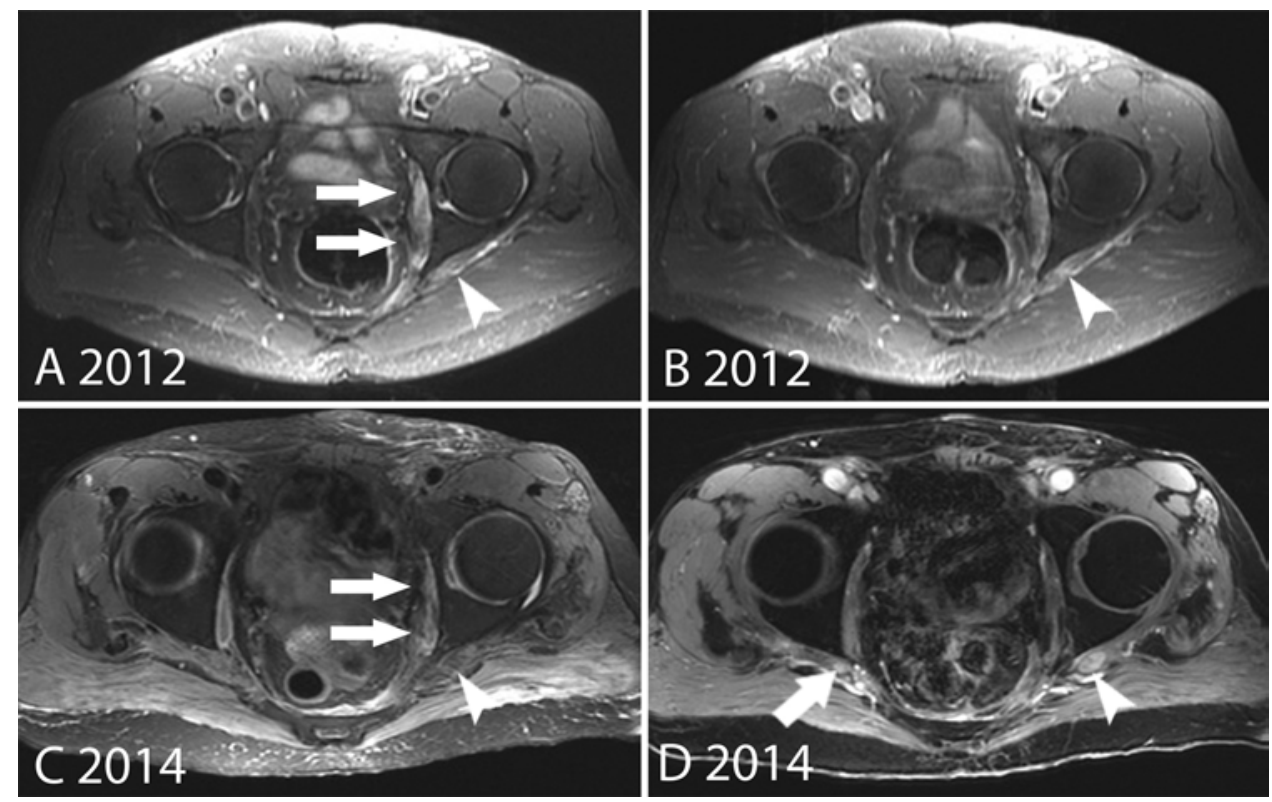

FIG. 2. A and B: Axial T2-weighted fat-saturated MR images obtained in March 2012 before $(A)$ and after (B) gadolinium administration demonstrating asymmetrical increased T2 signal of the left proximal sciatic nerve (A, arrowhead) with reticulated peripheral enhancement ( $B$, arrowhead). Although perifascicular enhancement is typical for perineural tumor spread, the enlargement and increased T2 signal are not and may be seen with radiation neuritis as well. The left obturator internus muscle demonstrated increased intramuscular T2 signal (A, arrows), which is a nonspecific finding that can be seen with muscle inflammation, injury, or denervation changes. C and D: Similar axial MR images of the pelvis from a lumbosacral plexus examination performed 2 years later demonstrating marked progression of the left sciatic nerve findings. The nerve demonstrates a heterogeneous appearance with increased and decreased areas of T2 signal (C, arrowhead). The post-gadolinium image (D, arrowhead) demonstrates a fusiform infiltrating pattern of enhancement that is highly worrisome for perineural spread of disease given the patient's clinical history. The tibial division of the right sciatic nerve ( $D$, arrow) now demonstrates an infiltrative pattern of enhancement worrisome for contralateral perineural spread of tumor. Marked changes of acute on chronic denervation are now present in the left hemipelvis, including worsening of the left obturator internus atrophy ( $\mathrm{C}$, arrows).

PET/CT scans of the pelvis and the trunk. MRI of the head showed no metastatic disease. MRI of the lumbosacral plexuses demonstrated enhancing and enlarged left L-4, L-5, and S-1 nerves and nodular enhancing and enlarged S-2 and S-3 nerves bilaterally, continuous with an enhancing lesion in the sacral canal at the S1-2 level (Fig. $3 \mathrm{C}$ and $\mathrm{E}$ ). It further demonstrated bilaterally enhancing sciatic nerves (Fig. 2D). These MRI findings were highly suggestive of bilateral perineural tumor spread within the lumbosacral plexuses. Pharmacokinetic perfusion analysis and diffusion-weighted imaging showed several foci of restricted diffusion and increased perfusion in the left ischial bone, in the pubic bones bilaterally, and in the sacrum. The ${ }^{11} \mathrm{C}$-choline PET/CT scans showed increased uptake in the lesion in the sacral canal, the left L-5 nerve root, and the S-1 nerve roots bilaterally and in the same bony lesions visible on perfusion studies (Fig. 3D). The FDG PET/CT scan delineated the same abnormalities even more clearly (Fig. 3F).

\section{Procedures}

The patient underwent 2 lumbar punctures, which showed atypical lymphocytes of undetermined significance but no prostate cancer cells. The PSA level measured in the cerebrospinal fluid (CSF) was $49.6 \mathrm{ng} / \mathrm{ml}$. Diffuse perineural invasion by prostate adenocarcinoma was confirmed by biopsy of the tibial division of the left sciatic nerve just distal to the sciatic notch (Fig. 4).

\section{Postoperative Course}

The patient recovered from the surgery without complications. He continued to receive hormonal therapy, and chemotherapy was scheduled.

\section{Discussion}

In this article we present a patient who we believe demonstrates sequential perineural spread from the prostate bed to the left lumbosacral plexus and subsequently to the right lumbosacral plexus utilizing the dural sac as a bridge between left and right sacral nerves resulting in bilateral lumbosacral plexopathy (Fig. 5 and Video 1).

VIDEO 1. Animated figure demonstrating the proposed spread of prostate cancer to the lumbosacral plexus (solid arrows) and then to the contralateral sciatic nerve utilizing the dural sac as a bridge between the contralateral spinal nerves (dashed arrows). By permission of Mayo Foundation for Medical Education and Research. All rights reserved. Click here to view with MediaPlayer. Click here to view with Quicktime.

Our theory is supported by progression on the imaging studies and progression of the clinical symptoms, which preceded the imaging evidence by several months. Although no cancer cells were identified in the CSF, the high PSA level measured from the lumbar puncture supports the possibility of subsequent intradural seeding as an explanation for CNS metastases in patients with intradural extension.

Although no similar case has yet been reported, review 

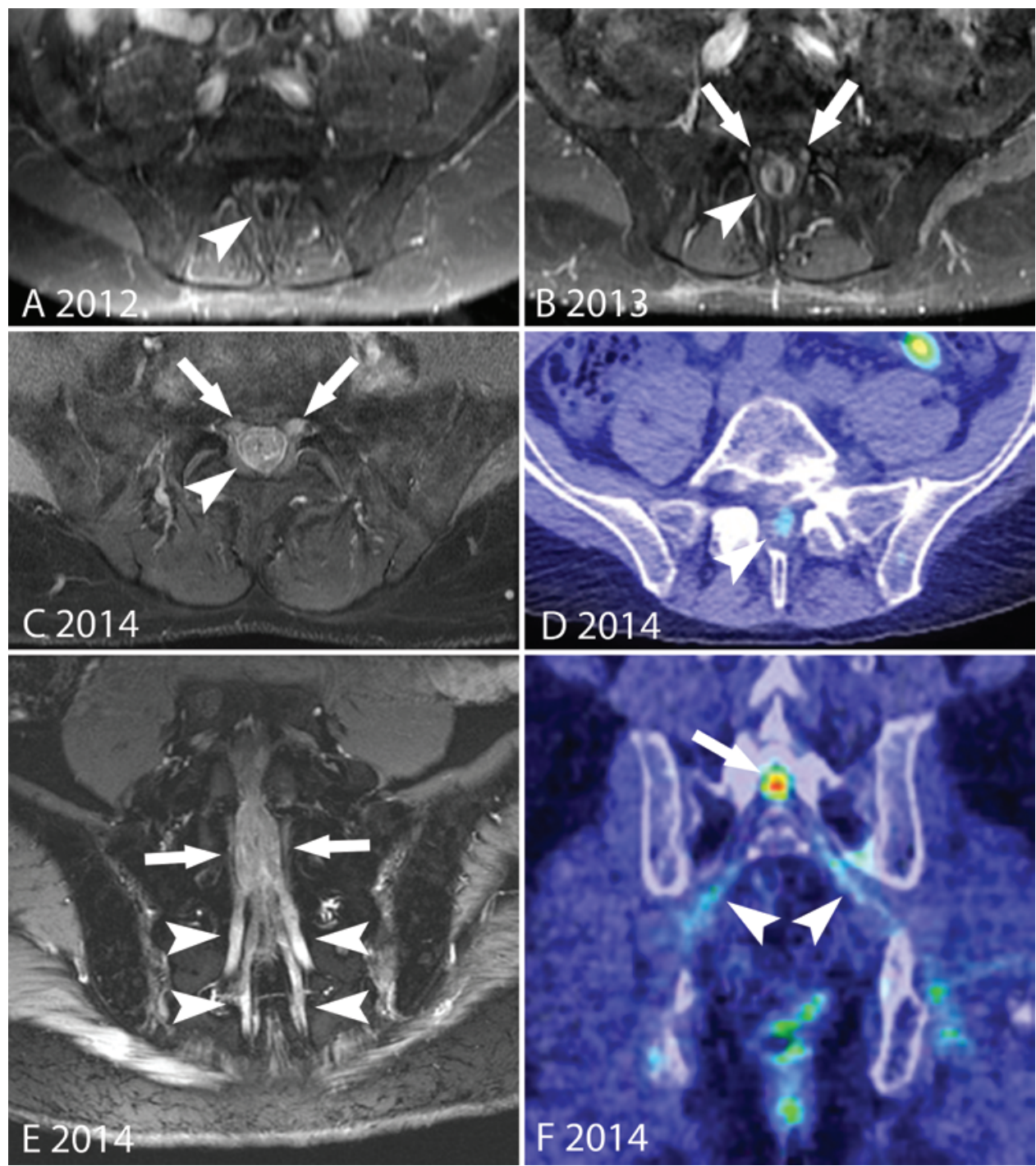

FIG. 3. A-C: Axial post-gadolinium T1-weighted MR images obtained at the S-1 level showing sequential progression of the dural sac involvement with the tumor. In 2012, only an enhancing pattern of the dural sac was noticeable (A, arrowhead); this progressed to a circumferential tumor mass in 2013 (B, arrowhead). The left S-1 nerve root shows enhancement, but the right shows little to no enhancement (B, arrows). In 2014 the sacral canal was dilated by the heterogeneously enhancing tumor mass (C, arrowhead) and the S-1 nerve roots were enlarged and enhancing bilaterally (C, arrows). D: Axial fused ${ }^{11} \mathrm{C}$-choline PET/CT image showing increased uptake in the sacral canal mass (arrowhead). E: Coronal oblique gadolinium-enhanced fat-saturated image of the sacrum demonstrating abnormal enhancement of the sacral nerve roots. The S-2 and S-3 nerve roots are demonstrated on this image (arrowheads). The abnormal sacral roots coalesce into an ill-defined intradural enhancing mass (arrows). F: Coronal fused FDG PET/CT image demonstrating increased uptake in the lesion in the sacral canal (arrow) and further delineating the L-5 nerve roots forming the sciatic nerves bilaterally (arrowheads).

of the literature revealed several articles to support our theory. The concept of perineural spread with dural extension has been shown in other cancers, $, 10,20$ even crossing the midline.$^{10}$ The ability of prostate cancer to spread over the dura is supported by the fact that dural metastases are 4 times more common than brain metastases ${ }^{5}$ and that prostate cancer is the main cause of dural metastases in men. ${ }^{16,18,21}$ Demetriades et al. ${ }^{8}$ reported a case of intradural metastasis of prostate cancer with bilateral symptoms. The patient presented with bilateral lower-leg weakness more prominent on the right and sensory disturbances 12 years after prostatectomy for prostate cancer. Three years after the onset of symptoms, the patient underwent lumbar laminectomy and debulking of an intrathecal tumor, with histology consistent with the original prostate cancer. The authors proposed perineural spread along the pudendal nerve as a possible explanation, but this is unlikely, as the pudendal nerve neither innervates the prostate nor runs in its close proximity. They did not provide any further evidence to support their theory, and they did not explain the patient's contralateral symptoms. We wonder if this case could be explained by our described mechanism.

The initial step of perineural spread is perineural invasion (PNI). In prostate cancer PNI is common and is seen in $7 \%-43 \%$ of biopsies ${ }^{11}$ and in $77 \%-93 \%$ of prostatectomy specimens from patients in whom previous biopsy 


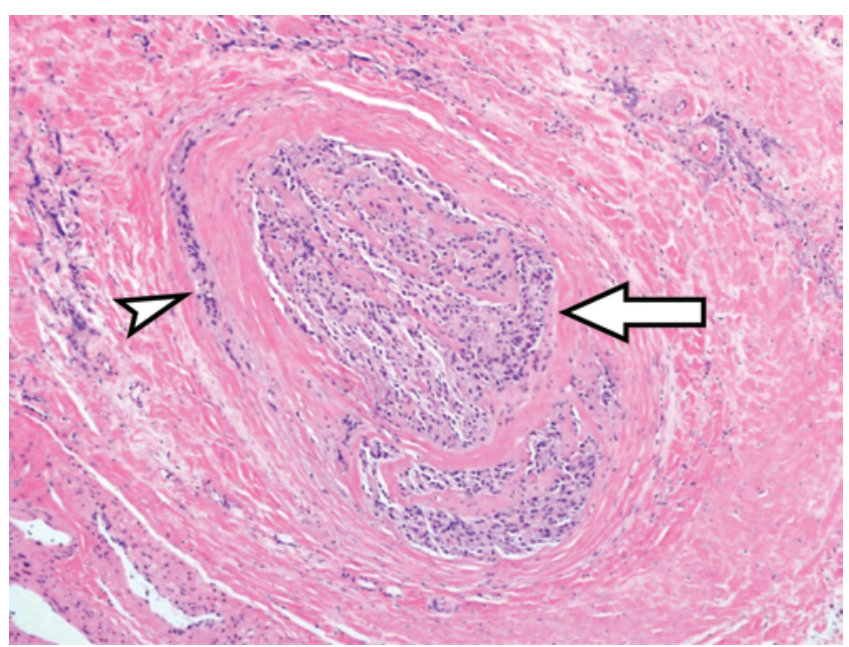

FIG. 4. Photomicrograph showing the histomorphological features of endoneurial (arrow) and perineurial (arrowhead) invasion with cancer cells. This specimen was obtained in 2014 from a fascicular biopsy from the tibial division of the left sciatic nerve. $\mathrm{H} \& \mathrm{E}$, original magnification $\times 100$.

was positive for PNI. ${ }^{4,13}$ Its prognostic value is still controversial, but in more recent studies primarily focused on PNI, it appears to be an independent prognostic factor associated with decreased survival and increased recurrence rate. ${ }^{1,6,7,11} \mathrm{PNI}$ is the major mechanism of prostate cancer spread outside the prostate gland. ${ }^{24}$

Nerves not only harbor cancer cells, but they appear to actively promote cancer cell penetration ${ }^{19}$ and survival and decrease apoptosis of the invading cells. ${ }^{2}$ Our understand- ing of the interactions between cancer cells and nerve is very limited and further research is called for.

We acknowledge that other possible explanations of this case exist. 1) The involvement of the contralateral plexus might not have followed a transmedian path from the left nerve roots to the right, but may have occurred as a result of parallel spread from the prostatic bed utilizing left and right pelvic and sacral splanchnic nerves simultaneously, only somewhat delayed on the right side. In this explanation, the sphincter problems might have been caused by bilateral infiltration of the pelvic autonomic nervous system even without the sacral canal mass. Considering the presence of the tumor mass pressing on the nerve roots and compelling findings on sequential imaging, our proposed explanation seems to be more likely. 2) The transmedian bridging may not have used the dural sac as a conduit but may have occurred by direct invasion of the contralateral nerve roots with the intradural sacral canal tumor mass or even by ascendant spread via the roots to the conus medullaris and then by descendant spread within the contralateral nerve roots. This possible explanation is not supported by imaging findings. 3) The blood-nerve barrier and the absence of lymphatic vessels within endoneurium render the hematogenous or lymphogenous metastasis to the plexuses unlikely. 4) Radiation injury as a cause of the patient's contralateral (right-sided) problems is unlikely. The radiation dose was well below the normal nerve tolerance, and radiation-induced plexopathy is usually accompanied by myokymia on EMG and affected nerves do not show enhancement on $\mathrm{MRI}^{15}$ - in contrast to our case.

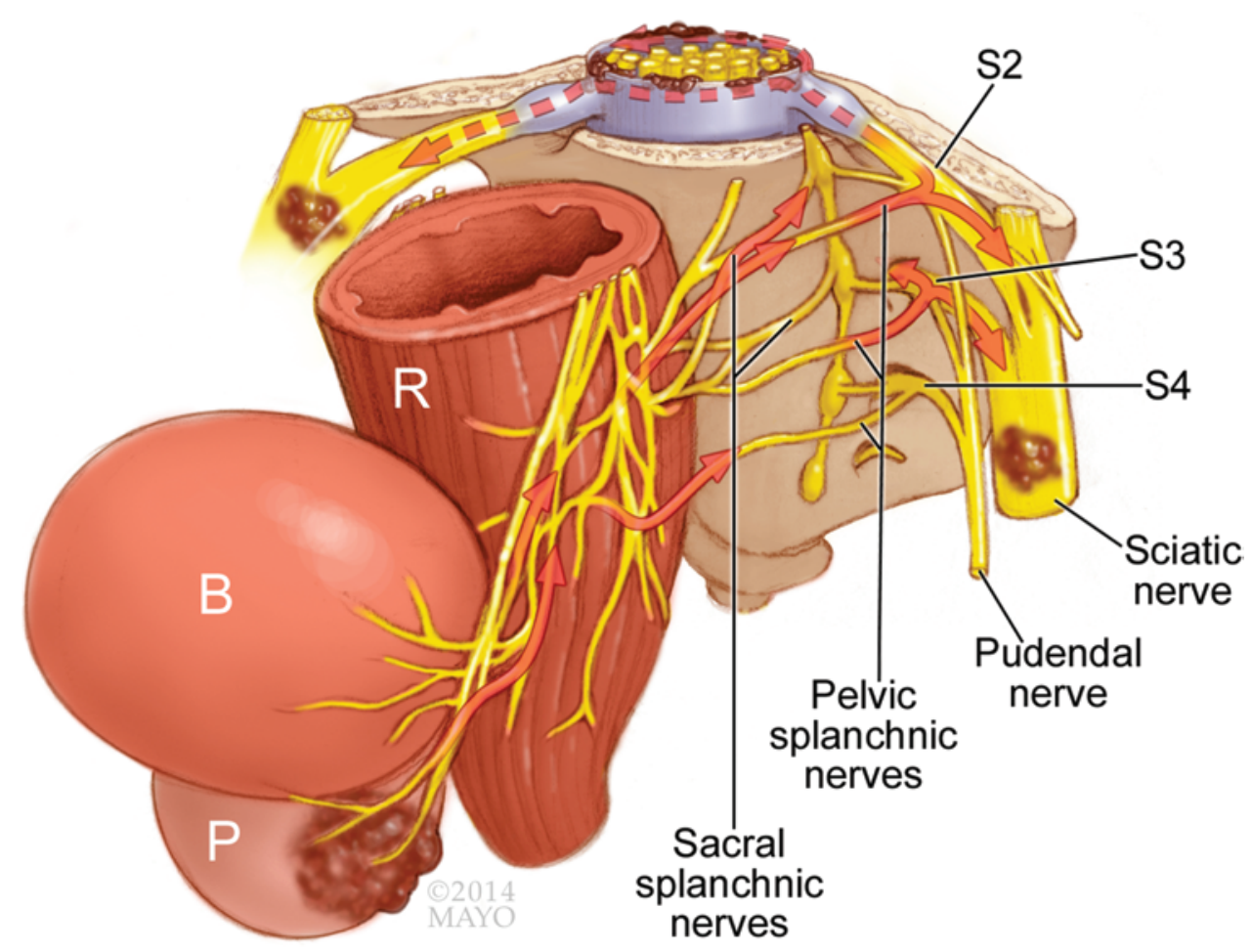

FIG. 5. The artistic rendition of the proposed mechanism of the prostate cancer perineural spread from the prostate to the lumbosacral plexus (solid arrows) and then to the contralateral sciatic nerve utilizing the dural sac as a bridge between the opposing spinal nerves (dashed arrows). $\mathrm{B}=$ bladder; $\mathrm{P}=$ prostate; $\mathrm{R}=$ rectum. By permission of Mayo Foundation for Medical Education and Research. All rights reserved. 


\section{Conclusions}

We present a case of bilateral lumbosacral plexopathy caused by perineural spread of prostate carcinoma. We correlate the sequential changes in clinical status with findings on high-resolution imaging to support the mechanism of perineural spread using the dural sac as a bridge between left and right sacral nerve roots.

\section{Acknowledgments}

We acknowledge the input and diligent work of the illustrators David Factor and David J. Cheney.

\section{References}

1. Aumayr K, Breitegger M, Mazal PR, Koller A, Marberger M, Susani M, et al: Quantification of extraprostatic perineural spread and its prognostic value in pT3a pNO M0 R0 prostate cancer patients. Prostate 71:1790-1795, 2011

2. Ayala GE, Dai H, Ittmann M, Li R, Powell M, Frolov A, et al: Growth and survival mechanisms associated with perineural invasion in prostate cancer. Cancer Res 64:6082-6090, 2004

3. Babu MA, Spinner RJ, Dyck PJ, Amrami KK, Nathan MA, Kawashima A, et al: Recurrent prostatic adenocarcinoma with perineural spread to the lumbosacral plexus and sciatic nerve: comparing high resolution MRI with torso and endorectal coils and F-18 FDG and C-11 choline PET/CT. Abdom Imaging 38:1155-1160, 2013

4. Bastacky SI, Walsh PC, Epstein JI: Relationship between perineural tumor invasion on needle biopsy and radical prostatectomy capsular penetration in clinical stage B adenocarcinoma of the prostate. Am J Surg Pathol 17:336-341, 1993

5. Bubendorf L, Schöpfer A, Wagner U, Sauter G, Moch H, Willi N, et al: Metastatic patterns of prostate cancer: an autopsy study of 1,589 patients. Hum Pathol 31:578-583, 2000

6. Cohn JA, Dangle PP, Wang CE, Brendler CB, Novakovic KR, McGuire MS, et al: The prognostic significance of perineural invasion and race in men considering active surveillance. BJU Int 114:75-80, 2014

7. DeLancey JO, Wood DP Jr, He C, Montgomery JS, Weizer AZ, Miller DC, et al: Evidence of perineural invasion on prostate biopsy specimen and survival after radical prostatectomy. Urology 81:354-357, 2013

8. Demetriades AK, Moussa W, Liebenberg WA, Critchley GR: Perineural spread of prostatic carcinoma presenting as lumbar intradural metastasis without bony involvement. Minerva Chir 66:372-373, 2011

9. Eisen MD, Yousem DM, Montone KT, Kotapka MJ, Bigelow DC, Bilker WB, et al: Use of preoperative MR to predict dural, perineural, and venous sinus invasion of skull base tumors. AJNR Am J Neuroradiol 17:1937-1945, 1996

10. Hanna E, Vural E, Prokopakis E, Carrau R, Snyderman C, Weissman J: The sensitivity and specificity of high-resolution imaging in evaluating perineural spread of adenoid cystic carcinoma to the skull base. Arch Otolaryngol Head Neck Surg 133:541-545, 2007

11. Harnden P, Shelley MD, Clements H, Coles B, TyndaleBiscoe RS, Naylor B, et al: The prognostic significance of perineural invasion in prostatic cancer biopsies: a systematic review. Cancer 109:13-24, 2007

12. Hébert-Blouin MN, Amrami KK, Myers RP, Hanna AS, Spinner RJ: Adenocarcinoma of the prostate involving the lumbosacral plexus: MRI evidence to support direct perineural spread. Acta Neurochir (Wien) 152:1567-1576, 2010

13. Holmes GF, Walsh PC, Pound CR, Epstein JI: Excision of the neurovascular bundle at radical prostatectomy in cases with perineural invasion on needle biopsy. Urology 53:752-756, 1999

14. Howe BM, Amrami KK, Nathan MA, Garcia JJ, Spinner RJ: Perineural spread of cervical cancer to the sciatic nerve. Skeletal Radiol 42:1627-1631, 2013

15. Jaeckle KA: Neurologic manifestations of neoplastic and radiation-induced plexopathies. Semin Neurol 30:254-262, 2010

16. Kleinschmidt-DeMasters BK: Dural metastases. A retrospective surgical and autopsy series. Arch Pathol Lab Med 125: $880-887,2001$

17. Ladha SS, Spinner RJ, Suarez GA, Amrami KK, Dyck PJ: Neoplastic lumbosacral radiculoplexopathy in prostate cancer by direct perineural spread: an unusual entity. Muscle Nerve 34:659-665, 2006

18. Laigle-Donadey F, Taillibert S, Mokhtari K, Hildebrand J, Delattre JY: Dural metastases. J Neurooncol 75:57-61, 2005

19. Li R, Wheeler T, Dai H, Ayala G: Neural cell adhesion molecule is upregulated in nerves with prostate cancer invasion. Hum Pathol 34:457-461, 2003

20. Maroldi R, Farina D, Borghesi A, Marconi A, Gatti E: Perineural tumor spread. Neuroimaging Clin N Am 18:413-429, xi, 2008

21. Nayak L, Abrey LE, Iwamoto FM: Intracranial dural metastases. Cancer 115:1947-1953, 2009

22. Siegel R, Ma J, Zou Z, Jemal A: Cancer statistics, 2014. CA Cancer J Clin 64:9-29, 2014

23. Uchida K, Kobayashi S, Yayama T, Muramatsu J, Kurokawa $\mathrm{T}$, Imamura Y, et al: Metastatic involvement of sacral nerve roots from uterine carcinoma: a case report. Spine J 8:849852,2008

24. Villers A, McNeal JE, Redwine EA, Freiha FS, Stamey TA: The role of perineural space invasion in the local spread of prostatic adenocarcinoma. J Urol 142:763-768, 1989

\section{Author Contributions}

Conception and design: Spinner, Capek, Amrami. Acquisition of data: Spinner, Capek, Howe, Tracy, García. Analysis and interpretation of data: all authors. Drafting the article: Spinner, Capek, Howe, García. Critically revising the article: all authors. Reviewed submitted version of manuscript: all authors. Approved the final version of the manuscript on behalf of all authors: Spinner. Administrative/technical/material support: Spinner, Capek. Study supervision: Spinner.

\section{Supplemental Information Videos}

Video 1, Media Player. http://mfile.akamai.com/21490/wmv/ digitalwbc.download.akamai.com/21492/wm.digitalsource-naregional/jns14-1339_video_1.asx.

Video 1, Quicktime. http://mfile.akamai.com/21488/mov/ digitalwbc.download.akamai.com/21492/qt.digitalsource-global/ jns14-1339_video_1.mov.

\section{Correspondence}

Robert J. Spinner, Mayo Clinic, 200 1st St. SW, Gonda 8-214, Rochester, MN 55905. email: spinner.robert@mayo.edu. 